\title{
Risks associated with the use of morphine for analgesia: attitudes and perceptions amongst nursing students in French-speaking Switzerland
}

This article was published in the following Dove Press journal:

Nursing: Research and Reviews

24 January 2013

Number of times this article has been viewed

\author{
Henk Verloo' \\ Christine Cohen' \\ Corinne Borloz' \\ Emmanuel K Mpinga ${ }^{2,3}$ \\ Philippe Chastonay ${ }^{3,4}$ \\ 'University of Applied Sciences, \\ Nursing, La Source, Lausanne, \\ Switzerland; ${ }^{2}$ Swiss School of Public \\ Health Plus, Zurich, Switzerland; \\ ${ }^{3}$ Institute of Social and Preventive \\ Medicine, ${ }^{4}$ Unit of Development \\ and Research in Medical Education, \\ Faculty of Medicine, University of \\ Geneva, Geneva, Switzerland
}

Aims: This paper reports on the attitudes and perceptions of risks associated with the use of morphine for analgesia among nursing students and explores the relationship between those attitudes and perceptions and sociodemographic data.

Background: Attitudes and perception of risks regarding the use of morphine for analgesia amongst nurses remain problematic, thus potentially leading to important consequences regarding the quality of pain management.

Methods: A cross-sectional survey among 557 nursing-students enrolled in the 3-year bachelor program was conducted in the French-speaking part of Switzerland from May to December 2010. The instrument's validity and internal reliability were tested before use. Twenty-two items evaluated attitudes and perception of risks when using morphine.

Results: Attitudes and perception of risks regarding the use of morphine for analgesia are evolving significantly during the 3 years of education. Sociodemographic data have little influence, if any, on attitudes and perception of risks.

Conclusion: The positive evolution of attitudes over the years of training pleads for the crucial role played by education regarding development of competency in pain management and nursing care.

Keywords: morphinophobia, attitudes, risk perception, nursing students, myths of morphine, theory of reasoned action

\section{Introduction}

\section{Background}

Myths concerning the use of opioids in pain management are still rampant among nurses. ${ }^{1-3}$ Despite the dissemination of guidelines supported by evidence-based research, nurses persist in retaining inappropriate attitudes regarding this domain., The use of morphine, in particular, remains problematic, sometimes leading to "morphinophobia". 1,6,7

Morphinophobia has been defined differently by various authors. It is either an ensemble of beliefs focused on the negative effects of morphine when used for pain management, ${ }^{8,9}$ or an inappropriate attitude in pain management resulting from a lack of knowledge about morphine and its appropriate use. ${ }^{10}$ Initial studies on this topic were published in the early 1960s by Robins and Murphy ${ }^{11}$ and by Abeles et al ${ }^{12}$ who examined attitudes and biases among physicians and health care settings guidelines regarding the use of morphine. Notably, they reported that the use of morphine in specific populations generates addiction problems with opioid or other illicit substance abuse. ${ }^{13}$
Correspondence: Henk Verloo University of Applied Sciences, Nursing La Source, Ave Vinet 30,

$\mathrm{CH}$ - 1004 Lausanne, Switzerland

Tel +4I 2I 64I 3860

Email henk.verloo@unil.ch
Nursing: Research and Reviews 2013:3 I-8

(C) 2013 Verloo et al, publisher and licensee Dove Medical Press Ltd. This is an Open Access article which permits unrestricted noncommercial use, provided the original work is properly cited.
Dovepress

http://dx.doi.org/10.2147/NRR.S3940/ 
According to Marchand, $80 \%$ of patients in various health care settings (hospitals, ambulatory, chronic care, and community care facilities) complain about pain. ${ }^{14}$ Recent studies confirm that the fear of opioid addiction or abuse by patients remains vivid among nurses and other health professionals working in hospitals. ${ }^{13,15-17}$ Morphine is often associated with misrepresentations linked to terminal illness, imminent death, drugs, or addiction. Doubts exist about its oral administration, as well as fear of side effects like death, euthanasia, excessive sedation, respiratory failure, or urine retention. ${ }^{8}{ }^{8} 18$ Furthermore, Barnett et al,${ }^{19}$ Gilson et al,${ }^{20}$ Jamison et al, ${ }^{15}$ and Zacny and Lichtor ${ }^{13}$ reported beliefs related to illicit drug use.

As established by social cognitive theory, many factors influence the behavior of nurses. ${ }^{21}$ This is also true when it comes to use and administration of opioids to patients. ${ }^{22}$ The theory of reasoned ${ }^{23}$ action serves as theoretical framework in this study. According to the Ajzen and Fishbein theory of reasoned action,,$^{23,24}$ the adoption of a behavior by an individual is the immediate result of the behavioral intention. This intention, in turn, can be predicted by the individual's attitudes and subjective norms toward the behavior. Attitudes consist in the individual's positive or negative evaluation of the behavior and are determined by the individual's beliefs regarding the consequences of the adoption of the behavior (behavioral beliefs) and his/her evaluation of these consequences (outcome evaluations). Subjective norms are individual perceptions of social pressure to perform or not to perform a particular behavior. These norms are determined by beliefs of the individual, that is, the individual's perception of the opinion of specific persons or groups about this behavior. These beliefs are counterbalanced by the individual's motivation to comply with the opinion of these specific persons or groups. In the theory of reasoned action, other external variables and phenomena, such as pertaining to personality or demographics, are considered peripheral to the theory and cannot help predict behavior. Nonetheless, Ajzen and Fishbein suggest that these beliefs can help understand attitudes and subjective norms. The theory of reasoned action ${ }^{24}$ is often used to study health-related behavior and provides a framework and operational definitions for studying attitudes and social norms. Given the dearth of studies evaluating nursing student attitudes toward morphine using, and given the importance of these variables in pain management, this study aims to assess Swiss nursing students' attitudes and perceptions regarding the risks associated with the use of morphine for analgesia. Because bachelor level nursing education is standardized in Europe, findings can be generalized more widely.

\section{Aims and research questions}

The study aims to describe attitudes and perceptions of risks regarding the use of morphine for analgesia and to explore the relationship with the sociodemographic characteristics of the nursing students. The following research questions are explored in this study: What are the attitudes and perceptions of risks regarding the use of morphine for analgesia among bachelor students in nursing? What is the impact of sociodemographic characteristics of nursing students on attitudes and perceptions of risks when morphine is used for analgesia?

\section{Design}

A cross-sectional descriptive study was conducted at the University Of Applied Sciences in French-speaking Switzerland from May to December 2010.

\section{Sample}

A convenience sample of Bachelor of Nursing students was recruited. The inclusion criteria were all students in Bachelor of Nursing of the first, second, and third years at the University of Applied Sciences in Western Switzerland of any age and sex.

\section{Data collection}

The data collection took place immediately following theoretical lectures, which may help explain the $80 \%$ response rate (the missing $20 \%$ is linked with sick leaves, internships, or students with specific individual educational programs). Participants completed a self-administered questionnaire developed by Musi and Bionaz. ${ }^{6}$ This tool is made of two sections: one dealing with items related to the use (and administration) of morphine for analgesia and a second dealing with risks when morphine is used. A five-level Likert-type scale, ranging from "totally disagree" (1) to "totally agree" (5) was used. A low score (1 to 2 ) shows a positive attitude and the perception that risks are acceptable when using morphine for analgesia. Conversely, a high score (3 to 5) displays a negative attitude toward use and the perception of high risks when using morphine for analgesia. A backward/forward translation in English has been applied to translate the questionnaire.

\section{Ethical considerations}

The internal advisory boards of the different multisite Universities of Applied Sciences in Western Switzerland provided an email authorization. All participating students received an explanation and were informed about the aim of the study. They signed consent forms and were reassured about confidentiality. The collected data were encoded and 
kept locked. The results are displayed as aggregate data to respect the confidentiality and anonymity of the responders.

\section{Data analysis}

The instrument validity and reliability were evaluated using exploratory factor analysis (EFA) and Pearson's Chi squared test or Fisher's Exact test were used to assess differences for categorical data. Scores for the two survey sections are reported using descriptive statistics. Analyses of variance (ANOVA) analysis was used to compare the three educational years of the Bachelor of Nursing program.

The relationship between the attitudes and perceptions of students and sociodemographic characteristics were assessed with the nonparametric test Spearman's correlation coefficient (Rhô) with scores between 0 and 0.200 (positive or negative) being considered a weak association; scores between 0.201 and 0.500 (positive or negative) are considered as moderate; and correlation scores of 0.501 and above (positive or negative) are considered as strong. ${ }^{25} \mathrm{~A} P$-value of $<0.05$ was considered as statistically significant. The analyzes were carried out using IBM-SPSS software (version 19.0; IBM, Armonk, NY, USA). ${ }^{26}$

\section{Validity and reliability of the instrument}

In order to ensure the validity and reliability of the instrument, a pretest involving 50 students was carried out. A KaiserMeyer-Olkin test with a score of 0.786 and a Bartlett's sphe- ricity test with a score of $2593.765(P=0.000)$ confirmed the possibility to analyze our 557 questionnaires with an EFA. To identify variables' clusters about attitudes and perceptions of risk, orthogonal varimax rotation has been applied. ${ }^{25}$ The items dealing with the use of morphine show a four-componentstructure (eigenvalue), and explain $46 \%$ of the initial variance. After two orthogonal varimax rotations, two items were abandoned (representing an eigenvalue of $<0.3$ ). The items dealing with perceptions of risks when using morphine show a three-component-structure (eigenvalue) explaining 64\% of the initial variance. After two orthogonal varimax rotations and the abandonment of weak correlations, all items presented an eigenvalue of $>0.3$. Cronbach's alpha was used to test the internal reliability; the items dealing with the use of morphine show a 0.52 coefficient, and the items regarding risks when using morphine as analgesia show a 0.70 coefficient. The global Cronbach's alpha is 0.74 .

\section{Results}

Sociodemographic variables are summarized in Table 1. Among 810 distributed questionnaires, 730 were returned, 50 questionnaires were used for pretesting the instrument, and 123 were incomplete and excluded from analysis, which left 557 questionnaires for analysis in the sample (68.8\%).

\section{Sociodemographic data}

There was a significant (logical) difference regarding age, opposing each bachelor year $(P=0.000)$. No significant

Table I Features of bachelor of nursing students

\begin{tabular}{|c|c|c|c|c|}
\hline Characteristics & $\begin{array}{l}\text { Bachelor first year } \\
(n=186)\end{array}$ & $\begin{array}{l}\text { Bachelor second year } \\
(n=174)\end{array}$ & $\begin{array}{l}\text { Bachelor third year } \\
(n=197)\end{array}$ & $P$-value \\
\hline \multicolumn{5}{|l|}{ Sex } \\
\hline Male & $28(34.6)^{\mathrm{a}}$ & $22(27.2)^{\mathrm{a}}$ & $31(38.3)^{\mathrm{a}}$ & 0.809 \\
\hline Female & $158(33.3)^{\mathrm{a}}$ & $152(32.0)^{\mathrm{a}}$ & $165(34.7)^{\mathrm{a}}$ & \\
\hline \multicolumn{5}{|l|}{$A g e^{b-d}$} \\
\hline$<23.6$ years & $122(45.9)^{\mathrm{a}}$ & $97(36.5)^{\mathrm{a}}$ & $47(17.7)^{\mathrm{a}}$ & $0.00 I^{*}$ \\
\hline$\geq 23.6$ years & $57(20.5)^{\mathrm{a}}$ & $75(27.0)^{\mathrm{a}}$ & $146(52.5)^{\mathrm{a}}$ & \\
\hline \multicolumn{5}{|l|}{ Dwelling environment } \\
\hline City & $44(36.1)^{\mathrm{a}}$ & $37(30.3)^{\mathrm{a}}$ & $4 I(33.6)^{\mathrm{a}}$ & 0.727 \\
\hline Suburban & $47(30.1)^{a}$ & $55(35.1)^{\mathrm{a}}$ & $54(34.6)^{\mathrm{a}}$ & \\
\hline Country & $93(33.7)^{a}$ & $82(29.7)^{a}$ & $101(36.6)^{\mathrm{a}}$ & \\
\hline \multicolumn{5}{|l|}{ Religion } \\
\hline Catholic & $102(35.3)^{a}$ & $87(30.1)^{\mathrm{a}}$ & $100(34.6)^{a}$ & 0.831 \\
\hline Protestant & $38(31.7)^{\mathrm{a}}$ & $40(33.3)^{\mathrm{a}}$ & $42(35.0)^{\mathrm{a}}$ & \\
\hline No religion & $26(37.1)^{\mathrm{a}}$ & $21(30.0)^{\mathrm{a}}$ & $23(32.9)^{\mathrm{a}}$ & \\
\hline Others & $17(3 \mid .5)^{\mathrm{a}}$ & $19(35.2)^{\mathrm{a}}$ & $18(33.3)^{\mathrm{a}}$ & \\
\hline \multicolumn{5}{|l|}{ Nationality } \\
\hline Swiss & $140(32.3)^{\mathrm{a}}$ & $144(33.2)^{a}$ & $150(34.6)^{\mathrm{a}}$ & 0.282 \\
\hline European Union (EU) & $38(38.4)^{\mathrm{a}}$ & $24(24.2)^{\mathrm{a}}$ & $37(37.4)^{\mathrm{a}}$ & \\
\hline Non-EU & $8(40.0)^{a}$ & $4(20.0)^{\mathrm{a}}$ & $8(40.0)^{\mathrm{a}}$ & \\
\hline
\end{tabular}

Notes: a Percent among the participants; ${ }^{b}$ mean among the participants; ${ }^{c}$ age range of participants: $19-54$ years; ${ }^{d}$ median age of participants: 23 years. $*$ Significance $P \leq 0.05$. 
difference was observed in religion $(P=0.831)$, sex $(P=0.809)$, residence $(P=0.727)$, and nationality $(P=0.282)$ between the 3 years of nursing students. Nursing students are predominantly female ( $85.4 \%$ ). The mean age is 23.6 (range 19-54) years. Students living in cities, semiurban environments, or the countryside are equally split. About half are Catholic (51.9\%), about one fifth are Protestant $(21.5 \%)$, about one tenth declare being without religion (13.1\%), and $10.1 \%$ declare other religious practices. More than threequarters of students are Swiss (82\%), and the remaining $18 \%$ belong to the European Union (Table 1).

\section{Attitudes regarding the use of morphine for analgesia}

Significant differences occurred between students attending the first year of the program and the second- and third-year cohorts regarding the use of morphine for analgesia when considering the following points:

- Patients can quickly get used to morphine and risk increasing the dose $(P=0.000)$;

- Once the treatment is initiated, the risk exists and can't be stopped $(P=0.000)$;

- Everyone can take morphine regardless of the type of pain $(P=0.000)$;

- Patients are against the prescription of morphine $(P=0.000)$;

- It is difficult to use and dose morphine correctly $(P=0.000)$;

- Morphine is a last-resort medication $(P=0.000)$.

No significant mean scores between the different bachelor years were observed for the following items: "Early use of morphine tends to prevent the recourse to any other treatment in case of intense pain" ( $P=0.001)$; "One can stop taking morphine whenever one wants to" $(P=0.001)$; "For old people, the pain sensation decreases with age, so use of morphine is not justified" ( $P=0.006)$; and finally, "The prescription of morphine must be avoided for patients in the terminal phase" $(P=0.222)$.

We observed some similar results among the Bachelor of Nursing students. Participants in all 3 years shared the perspective that "The prescription of morphine means that there is no survival expectation," presenting the lowest mean scores $(P=0.612)$. In contrast, and despite evidencebased clinical guidelines to the item "Venous administration is more efficient than oral administration" presenting the highest mean scores, students across the three different Bachelor of Nursing years show agreement $(P=0.491)$. Nevertheless, nursing students display high mean scores with the use of morphine of 2.41, 2.31, and 2.24, respectively (Table 2).

\section{Perception of risks regarding the use of morphine for analgesia}

Significant differences in perceptions of risk for delirium, euphoria, and urinary retention occurred between students attending the first year of the program and the second and third year groups $(P \leq 0.000)$.

No significant mean scores were also observed between the different bachelor years for the following items: "Risk of physical or psychological dependency" $(P=0.001)$; "Risk of dependency" $(P=0.033)$; "Heavier constraints compared to other medications" ( $P=0.143)$; and "Risk of respiratory failure" $(P=0.381)$.

The means dealing with perceptions of risks display the same sharing as the means dealing with the use of morphine. The item "Risk of discrimination" shows mild disagreement for each year $(P=0.014)$ and represents the lowest mean scores. Opposed to evidence-based clinical guidelines, the item "Risk of sedation" displays a high occurrence risk: 4.38 for the first year, 4.34 for the second year, and 4.26 for the third year of the program $(P=0.340)$ and represents the highest mean scores.

The mean of all items dealing with risks regarding the use of morphine split by program year is 3.59 for the first year, 3.33 for the second, and 3.28 during the third year $(P=0.001)$ (Table 2).

The general mean including attitudes and perceptions of risks regarding the use of morphine is 3.00 for the first-year students, 2.82 for the second-year students, and 2.76 for third-year students. This mean-analysis displays a significant difference of attitude and perception of risks regarding the use of morphine, opposing the students attending different years $(P=0.001)$, more precisely, the difference exists especially between the junior students (first year) and the remainder.

These results sustain the hypothesis that pharmacology knowledge of morphine use (pharmacology courses are organized in second and third year) and practical nursing experiences in health care settings facilitates morphine use for analgesia and the risk perception.

\section{Relationship between sociodemographic characteristics, attitudes, and perception of risks when morphine is used for analgesia}

Spearman's correlation coefficient (Spearman's Rhô: $r_{s}$ ) confirms the existing relationship between sociodemographic characteristics (age, dwelling environment, religion, and 
Table 2 Means, standard deviations, analyses of variance, attitudes and perceptions of risks when using morphine, related to bachelor year

\begin{tabular}{|c|c|c|c|c|c|c|c|c|}
\hline & \multicolumn{2}{|c|}{ First year } & \multicolumn{2}{|c|}{ Second year } & \multicolumn{2}{|c|}{ Third year } & \multicolumn{2}{|c|}{ ANOVA } \\
\hline & Mean & SD & Mean & SD & Mean & SD & $\mathbf{F}$ & $P$ \\
\hline \multicolumn{9}{|l|}{ Declarations $^{a}$} \\
\hline \multicolumn{9}{|l|}{ Items related to morphine use ${ }^{b}$} \\
\hline Patients can quickly get used to morphine and risk increasing the dose $(2.89)^{\mathrm{b}}$ & 3.31 & 1.152 & 2.83 & 1.338 & 2.54 & 1.297 & 18.126 & $0.000 *$ \\
\hline Once the treatment is initiated, the risk exists and can't be stopped $(2.12)^{\mathrm{b}}$ & 2.50 & 1.225 & 1.99 & 1.195 & 1.89 & 1.080 & 14.409 & $0.000 *$ \\
\hline Morphine is a last-resort medication $(2.24)^{\mathrm{b}}$ & 2.54 & 1.235 & 2.28 & 1.215 & 1.91 & 1.095 & 13.919 & $0.000 *$ \\
\hline It is difficult to use and dose morphine correctly $(2.26)^{\mathrm{b}}$ & 2.49 & I.III & 2.32 & 1.224 & 1.99 & 1.095 & 9.456 & $0.000 *$ \\
\hline Everyone can take morphine regardless of the type of pain $(2.07)^{\mathrm{b}}$ & 1.76 & 1.081 & 2.12 & 1.313 & 2.32 & 1.400 & 9.390 & $0.000 *$ \\
\hline Patients are against the prescription of morphine $(2.8 \mathrm{I})^{\mathrm{b}}$ & 2.59 & 1.022 & 3.01 & 0.982 & 2.84 & 1.010 & 8.192 & $0.000 *$ \\
\hline One can stop taking morphine whenever one wants to $(2.88)^{\mathrm{b}}$ & 2.62 & 1.234 & 2.90 & 1.347 & 3.11 & 1.203 & 7.051 & 0.001 \\
\hline $\begin{array}{l}\text { Early use of morphine tends to prevent the recourse to any other treatment } \\
\text { in case of intense pain }(2.92)^{\mathrm{b}}\end{array}$ & 3.21 & 1.279 & 2.83 & 1.360 & 2.73 & 1.378 & 6.592 & 0.001 \\
\hline For old people, the pain sensation decreases with age, so use is not justified $(1.39)^{\mathrm{b}}$ & 1.50 & 0.878 & 1.22 & 0.681 & 1.44 & 0.988 & 5.085 & 0.006 \\
\hline The prescription of morphine must be avoided for patients in terminal care $(I .4 I)^{\mathrm{b}}$ & 1.49 & 0.804 & 1.34 & 0.808 & 1.39 & 0.830 & 1.511 & 0.222 \\
\hline Venous administration is more efficient than the oral administration (3.69) & 3.73 & 1.318 & 3.75 & 1.300 & 3.59 & 1.379 & 0.713 & 0.491 \\
\hline The prescription of morphine means that there is no survival expectation $(I .61)^{b}$ & 1.19 & 0.634 & 1.13 & 0.533 & 1.17 & 0.621 & 0.492 & 0.612 \\
\hline Means & $2.41^{\mathrm{c}}$ & & $2.31^{d}$ & & $2.24^{\mathrm{e}}$ & & & \\
\hline \multicolumn{9}{|l|}{ Items related to risk perception ${ }^{b}$} \\
\hline Risk of delirium or euphoria $(3.44)^{b}$ & 3.78 & 1.116 & 3.30 & 1.250 & 3.24 & 1.260 & 11.315 & $0.000 *$ \\
\hline Risk of urine retention $(3.44)^{\mathrm{b}}$ & 3.68 & 1.090 & 3.47 & 1.165 & 3.18 & 1.210 & 8.797 & $0.000 *$ \\
\hline Risk of physical or psychological dependency $(3.44)^{\mathrm{b}}$ & 3.72 & 1.190 & 3.33 & 1.268 & 3.27 & 1.192 & 7.469 & 0.001 \\
\hline Risk of discrimination $(2.19)^{\mathrm{b}}$ & 2.38 & 1.056 & 2.13 & 1.165 & 2.05 & 1.102 & 4.295 & 0.014 \\
\hline Risk of dependency (3.09) ${ }^{\mathrm{b}}$ & 3.31 & 1.417 & 2.98 & 1.379 & 2.99 & 1.305 & 3.419 & 0.033 \\
\hline Heavier legal constraints compared to other medications $(3.10)^{\mathrm{b}}$ & 3.21 & 1.156 & 2.95 & 1.303 & 3.13 & 1.339 & 1.949 & 0.143 \\
\hline Risk of sedation $(4.32)^{b}$ & 4.38 & 0.764 & 4.34 & 0.816 & 4.26 & 0.832 & 1.082 & 0.340 \\
\hline Risk of respiratory failure $(4.20)^{\mathrm{b}}$ & 4.28 & 0.930 & 4.16 & 1.071 & 4.16 & 1.038 & 0.941 & 0.381 \\
\hline Means & $3.59^{f}$ & & $3.33^{\mathrm{g}}$ & & $3.28^{\mathrm{h}}$ & & & \\
\hline Sum of means & $6.00^{\circ}$ & & 5.64 & & $5.52^{\mathrm{k}}$ & & & \\
\hline
\end{tabular}

Notes: "“Totally disagree" (I) to "Totally agree" (5); ${ }^{b}$ mean of the Bachelor of Nursing students; ' $m e a n$ for the first year student regarding morphine use; ${ }^{d}$ mean for the second

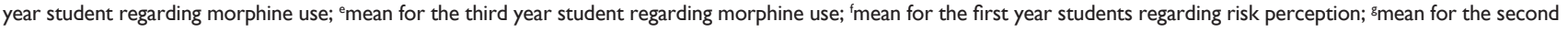
year students regarding risk perception; ${ }^{h}$ mean for the third year students regarding risk perception; 'sum of means first year students regarding morphine use and risk perception; isum of means second year students regarding morphine use and risk perception; "sum of means third year students regarding morphine use and risk perception. $* P<0.00 \mathrm{I}$.

Abbreviations: ANOVA, analysis of variance; SD, standard deviation.

nationality) and the use and perceptions of risks related with the use of morphine for analgesia. Sex was not considered in this analysis as $85.4 \%$ of the population is female (Table 1 ). Table 3 displays the correlation coefficients.

\section{Age}

Age shows a weak to moderate relationship with the items related to the use of morphine. Generally, if age increases, the agreement with the affirmation tends to decrease. This is the expected pattern as we remember that the affirmations are incorrect in this context.

- "Patients can quickly get used to morphine and risk increasing the dose" shows a moderate negative correlation $(P=0.001)$;

- "Once the treatment is initiated, the risk exists and can't be stopped" shows a weak negative correlation $(P=0.043)$;

- "Early use of morphine tends to prevent the recourse to any other treatment in case of intense pain" shows a weak negative correlation $(P=0.005)$;
- "It is difficult to use and to dose morphine correctly" shows a moderate negative correlation $(P \leq 0.000)$.

Regarding the perception of risks when using morphine for analgesia, the following items show significant correlations, signaling that younger students are more apprehensive:

- "Risk of respiratory failure" shows a weak correlation $(P=0.009)$;

- "Heavier legal constraints compared to other medications" shows a weak correlation $(P=0.001)$.

\section{Dwelling environment}

A weak correlation is found among the use of morphine items and dwelling places of this collective. Urban students show less agreement with the following items:

- "Everyone can take morphine regardless of the type of pain" shows a weak negative correlation $(P=0.012)$;

- "For old people, the pain sensation decreases with age, so use is not justified" shows a weak correlation $(P=0.018)$. 
Table 3 Correlations between sociodemographic characteristics, attitudes and perceptions of risks when using morphine for analgesia

\begin{tabular}{|c|c|c|c|c|c|c|c|c|}
\hline \multirow[t]{2}{*}{ Declarations related to morphine use and risk perception } & \multicolumn{2}{|l|}{ Age $^{a}$} & \multicolumn{2}{|c|}{ Residence $^{b}$} & \multicolumn{2}{|c|}{ Religion ${ }^{c}$} & \multicolumn{2}{|c|}{ Nationality ${ }^{d}$} \\
\hline & $\mathbf{r}_{\mathrm{s}}^{\mathrm{e}}$ & $P *$ & $r_{s}^{e}$ & P* & $\mathbf{r}_{\mathrm{s}}{ }^{\mathrm{e}}$ & $P *$ & $\mathbf{r}_{\mathrm{s}}^{\mathrm{e}}$ & $P *$ \\
\hline Patients can quickly get used to morphine and risk increasing the dose & $-0.154 *$ & 0.001 & -0.001 & 0.988 & 0.028 & 0.539 & 0.060 & 0.195 \\
\hline Once the treatment is initiated, the risk exists and can't be stopped & $-0.093 *$ & 0.043 & -0.009 & 0.842 & -0.028 & 0.546 & -0.005 & 0.910 \\
\hline Everyone can take morphine regardless of the type of pain & 0.020 & 0.665 & $-0.116^{*}$ & 0.012 & 0.027 & 0.564 & 0.031 & 0.507 \\
\hline $\begin{array}{l}\text { Early use of morphine tends to prevent the recourse to any } \\
\text { other treatment in case of intense pain }\end{array}$ & $-0.129 *$ & 0.005 & -0.005 & 0.914 & 0.011 & 0.819 & 0.028 & 0.545 \\
\hline Venous administration is more efficient than oral administration & -0.057 & 0.218 & 0.030 & 0.513 & -0.023 & 0.615 & 0.051 & 0.264 \\
\hline Patients are against the prescription of morphine & 0.047 & 0.306 & -0.073 & 0.112 & -0.019 & 0.673 & -0.044 & 0.340 \\
\hline $\begin{array}{l}\text { The prescription of morphine means that there is no survival } \\
\text { expectation }\end{array}$ & 0.023 & 0.619 & 0.027 & 0.561 & 0.038 & 0.410 & 0.014 & 0.757 \\
\hline It is difficult to use and dose morphine correctly & $-0.211 * *$ & 0.000 & -0.029 & 0.536 & $-0.117 *$ & 0.011 & 0.017 & 0.719 \\
\hline Morphine is a last-resort medication & -0.064 & 0.164 & 0.011 & 0.819 & -0.044 & 0.340 & 0.046 & 0.319 \\
\hline One can stop taking morphine whenever one wants to & 0.069 & 0.132 & 0.073 & 0.113 & 0.004 & 0.927 & -0.017 & 0.708 \\
\hline $\begin{array}{l}\text { Prescription of morphine must be avoided for patients } \\
\text { in terminal phase }\end{array}$ & -0.076 & 0.100 & 0.067 & 0.146 & 0.009 & 0.851 & -0.005 & 0.912 \\
\hline $\begin{array}{l}\text { For old people, the pain sensation decreases with age, } \\
\text { so use is not justified }\end{array}$ & -0.074 & 0.106 & $0.109 *$ & 0.018 & 0.010 & 0.830 & 0.079 & 0.086 \\
\hline Risk of dependency & 0.004 & 0.926 & 0.017 & 0.705 & $0.102 *$ & 0.026 & -0.001 & 0.976 \\
\hline Risk of sedation & 0.073 & 0.112 & -0.010 & 0.833 & -0.059 & 0.201 & -0.081 & 0.078 \\
\hline Risk of delirium or euphoria & -0.006 & 0.891 & -0.049 & 0.291 & 0.049 & 0.284 & $-0.127^{*}$ & 0.006 \\
\hline Risk of respiratory failure & $0.120 *$ & 0.009 & -0.011 & 0.811 & 0.042 & 0.357 & 0.013 & 0.776 \\
\hline Heavier legal constraints compared to other medications & $0.157^{*}$ & 0.001 & 0.028 & 0.540 & -0.020 & 0.659 & -0.069 & 0.132 \\
\hline Risk of physical and/or psychological dependency & -0.029 & 0.523 & 0.033 & 0.472 & 0.085 & 0.065 & -0.033 & 0.473 \\
\hline Risk of discrimination & 0.018 & 0.703 & 0.068 & 0.142 & 0.061 & 0.183 & -0.029 & 0.536 \\
\hline Risk of urine retention & -0.047 & 0.309 & 0.005 & 0.916 & -0.042 & 0.359 & $-0.138^{*}$ & 0.003 \\
\hline
\end{tabular}

Notes: ${ }^{\mathrm{a}}<23.6$ years $\geq 23.6$ years; ${ }^{\mathrm{b} C i t y}$ - Suburban - Country; 'Catholic - Protestant - No religion - Others; ${ }^{\mathrm{C} S}$ wiss - European Union (EU) - Non-EU; ${ }^{\mathrm{e} S p e a r m a n ' s}$ correlation coefficient (Spearman's Rhô: rs); *Significant correlation $<0.05$ (bilateral); **ignificant correlation < 0.0 (bilateral); $0-0.200$ (positive or negative): weak association; $0.20 \mathrm{I}-0.500$ (positive or negative) moderate association; $0.50 \mathrm{I}$ and above (positive or negative) strong association.

By contrast, no significant relationship linking dwelling place and perceptions of risks was found.

\section{Religion}

Religion is weakly and negatively correlated with the following affirmation: "It is difficult to use and dose morphine correctly" $(P=0.011)$.

The following risk item "Risks of dependency" shows a weak correlation $(P=0.026)$. Catholic students agreed more with the affirmations above.

\section{Nationality}

The two correlations with nationality are weak and negative for the use-related items "Risks of delirium or euphoria" $(P=0.006)$ and "Risks of urine retention" $(P=0.003)$. Swiss students are more reluctant to use morphine when considering delirium and euphoria risks. Other nationalities are more reluctant to use morphine because of urine retention risk.

\section{Discussion}

This study describes attitudes and perceptions of risks among Bachelor of Nursing students in western Switzerland when using morphine for analgesia. The sample is representative of the 3-year Bachelor of Nursing curriculum at the Universities of Applied Sciences in the French-speaking part of Switzerland. The results suggest that the use and perceptions of risks when using morphine for analgesia are far from optimal. Furthermore, these attitudes are diverse and are influenced by several factors. A lack of pharmacological knowledge and myths about morphine effects regarding risks when using morphine for analgesia are real among the studied population of future nurses. Notably fear was more important among first-year students compared to second- and thirdyear students. Fears relate to the negative representations of possible addiction, the inappropriate access to morphine for certain patients, the difficulties of measuring morphine level and possible side effects like delirium or urine retention.

Nevertheless, apprehensive attitudes when using morphine as an analgesic exist also among second- and third-year students albeit to a lesser extent. The aggregate mean for the 3 years shows an important fear related to risks when using morphine (2.86). This fear implies a lack of knowledge about action, side effects, administration forms and therapeutic precautions while using morphine, as has been previously 
described by Elliott and Elliot. ${ }^{10}$ This could lead to resistance to administrating morphine to patients suffering from severe pain. Such reluctance can have a negative impact on pain management as to the quality of life. ${ }^{1,27}$ Results from the present study are in line with previous reports on morphinophobia among health professionals by Broekmans et $\mathrm{al}^{28}$ and Edwards et $\mathrm{al}^{22}$ Several studies demonstrate that a good knowledge of pain mechanisms and the certitude of pharmacological efficacy favorably influence attitudes toward the use of morphine. ${ }^{22,28,29}$ However, knowledge alone is rather insufficient to guarantee its application, nor to induce a knowledge-based behavior. Attitudes related to behavior develop over a long time period and are linked to a social context. ${ }^{23,24}$

The Bachelor of Nursing students develop their competencies using a variety of knowledge, learned skills, and interpersonal skills during the 3 -year curriculum. ${ }^{30-32}$ These skills are strengthened through internships and professional experiences in various institutions. The educational system is based on the construction of professional competencies in real situations. ${ }^{30-32}$

The analysis of correlations between sociodemographic characteristics and the opinions about the use of morphine are weak. Younger nursing students are stronger correlated with fears when looking at attitudes and perceptions of risks.

In light of previous studies, these results are encouraging, 6,10,33 but myths about morphine are still shaping attitudes and perceptions of health professionals, nurses included, influencing its use. Consequently, it is important that educational institutions deconstruct these myths early in their curricula to raise students' awareness of the complexity of morphine use in clinical settings and enhance specific competency building ${ }^{31}$ opportunities in relation to pain management. Indeed such competencies following evidence-based nursing and evidencebased medicine guidelines are critical for professional expertise as well as value sharing on perceptions, attitudes, and behaviors. ${ }^{18,20,29,34-38}$ The planned clinical behavior theory developed by Ajzen ${ }^{23}$ could be of great help in this matter as it provides a comprehensive framework for understanding the acquisition of professional skills and competencies while providing insight into this important topic. ${ }^{23}$

This study has several limitations. First, we only describe the attitudes and perceptions of the students regarding risks when using morphine. We did not explore their knowledge about pain management nor about the administration of morphine. A second weakness concerns the Cronbach's alpha internal consistence of the items dealing with the use of morphine $(\alpha=0.52)$. This suggests the instrument could be improved. Furthermore, as this study is descriptive, it does not allow us to examine attitudes; we only assess predetermined contributing factors. As such, it would be useful to know more about the opinions of teachers in the universities of applied sciences (nursing programs) as well as opinions of trainers and nurses at institutions where the internships take place.

\section{Conclusion}

Similar to professional nurses, the Bachelor of Nursing students display an apprehensive attitude regarding the use of morphine for analgesia. With additional training this attitude improves as second- and third-year students have a slightly more favorable attitude regarding the use and the perception of risks when using morphine. The observation that sociodemographic characteristics scarcely influence the attitudes of nursing students points to the key role of training institutions in shaping views and practices of pain management.

Training institutions such as the University of Applied Sciences in Nursing are important players in transmitting knowledge and develop competencies related to adequate pain management and the role of morphine in analgesia. The adoption of a cognitive clinical learning model to develop the clinical nursing competency should be considerate. ${ }^{39,40}$

Despite growing attention to pain management still needs to be improved. The present findings suggest that pain management and morphine use knowledge should be integrated and/or strengthened in the training of future nurses. Indeed, caring for a human being experiencing pain is a major preoccupation of our profession, illustrating, among other things, the autonomy of nurses and their role in advocating for patients. More research is needed to gain a deeper understanding of the attitudes and fears of professionals regarding the use of morphine, with the objective to detect, measure, and optimally manage the pain of patients. A follow-up study of nursing students assessing the evolution over the curriculum could yield interesting information to explain the changes in attitudes and perceptions regarding risk and use of morphine for analgesia.

\section{Acknowledgments}

The authors thank the teachers, professors, students, and University of Applied Sciences of Western Switzerland for their precious collaboration. This research received no specific grant from any funding agency in the public, commercial, or not-for-profit sectors. Study concept: Emmanuel Mpinga Kabengele, Philippe Chastonay, Henk Verloo; Survey and data collection: Henk Verloo, Corinne Borloz, Christine Cohen; Data analysis and interpretation: Christine Cohen, Corinne Borloz, Henk Verloo; Writing: Henk Verloo, Emmanuel 
Mpinga Kabengele, Philippe Chastonay, Corinne Borloz, Christine Cohen; Follow-up: Henk Verloo, Philippe Chastonay, Emmanuel Mpinga Kabengele, Christine Cohen.

\section{Disclosure}

The authors report no conflicts of interest in this work.

\section{References}

1. Bandieri E, Chirarolanza A, Luppi M, et al. Prescription of opioids in Italy: everything but the morphine. Ann Oncol. 2009;20:961-962.

2. Ripamonti C, De Conno F, Blumhiber H, Ventafridda V. Morphine for relief of cancer pain. Lancet. 1996;347:1262-1263.

3. Verloo H, Ferreira M, Mpinga EK, Chastonay P, Rapin CH. Opiophobie: Etats des lieux auprès des soignants à Beira Intérior. [Opiophobia: State of the art among health care professionals in Beira Intérior]. Douleur et Analgésie. 2009;22:186-195. French.

4. World Health Organisation (WHO). Cancer Pain Relief, 2nd ed. Geneva: WHO; 1996. Available from: http://whqlibdoc.who.int/ publications/9241544821.pdf. Accessed August 2, 2011.

5. Gordon DB, Pellino TA, Miaskowski C, et al. A 10-year review of quality improvement monitoring in pain management: recommendations for standardized outcome measures. Pain Manage Nurs. 2002;3:116-130.

6. Musi M, Bionaz A. Les mythes de la morphine. Une étude auprès de la population générale, des infirmiers/ères et des médecins en Vallée d'Aoste. Infokara. 2003;4:1-18.

7. Verloo H, Mpinga EK, Ferreira M, Rapin CH, Chastonay P. Morphinofobia: the situation among the general population and health care professionals in North-Eastern Portugal. BMC Palliat Care. 2010;9:15

8. Tennant F. Overcoming opiophobia and doing opioids right. Pain Treatment Topics. Available from: http://pain-topics.org/pdf/overcomingopiophobia.pdf. Accessed August 2, 2011.

9. Covington EC. Opiophobia, Opiophilia, opioagnosia. Pain Med. 2000;1:217-223.

10. Elliott TE, Elliot BA. Physician attitudes and about use of morphine for cancer pain. J Pain Sympt Manage. 1992;7:141-148.

11. Robins LN, Murphy G. Drug use in a normal population of young Negro men. Am J Public Health Nations Health. 1967;57:1580-1597.

12. Abeles H, Plew R, Laudeutscher I, Rosenthal HM. Multiple-drug addiction in New York City in a selected population group. Public Health Rep. 1966;81:685-691.

13. Zacny JP, Lichtor S. Nonmedical use of prescription opioids: motive and ubiquity issues. J Pain. 2008;9:473-486.

14. Marchand S. Le Phénomène de la Douleur, 2nd Ed. Montréal, Canada: Chenelière Éducation; 2009.

15. Jamison RN, Ross EL, Michna E, Chen LQ, Holcomb C, Wasan AD. Substance misuse treatment or high-risk chronic pain patients on opioid therapy: a randomized trial. Pain. 2010;150:390-400.

16. McCaffery M, Grimm MA, Pasero C, Ferrell B, Uman GC. On the meaning of "drug seeking". Pain Manage Nurs. 2005;6:122-136.

17. Pillet S, Eschiti V. Managing chronic pain in patients with cancer who have a history of substance abuse. Clin J Oncol Nurs. 2008;12:663-667.

18. Vanegas G, Ripamonti C, Sbanotto A, De Conno F. Side effects of morphine administration in cancer patients. Cancer Nurs. 1998;21: 289-297.

Nursing: Research and Reviews

\section{Publish your work in this journal}

Nursing: Research and Reviews is an international, peer-reviewed, open access journal publishing original research, reports, reviews and commentaries on all aspects of nursing and patient care. These include patient education and counselling, ethics, management and organizational issues, diagnostics and prescribing, economics and
19. Barnett ML, Mulvenon CJ, Dalrymple PA, Connelly LM. Nurses' knowledge, attitudes, and practice patterns regarding titration of opioid infusions at the end of life. J Hosp Palliat Nurs. 2010;12:81-87.

20. Gilson AM, Maurer MA, Joranson DE. State medical board members' beliefs about pain, addiction, and diversion and abuse: a changing regulatory environment. J Pain. 2007;8:682-691.

21. Godin G, Bélanger-Gravel A, Eccles M, Grimshaw J. Healthcare professionals' intentions and behavior: A systematic review of studies based on social cognitive theories. Implement Sci. 2008;3:36.

22. Edwards H, Nash R, Najman, J, et al. Determinants of nurses' intention to administer opioids for pain relief. Nurs Health Sci. 2001;3:149-159.

23. Ajzen I. The theory of planned behavior. Organ Behav Hum Decis Process. 1991;50:179-211.

24. Fishbein M, Ajzen I. Belief, Attitude, Intention, and Behavior: An introduction to theory and research. Reading, MA: Addison-Wesley; 1975.

25. Hair JF, Black WC, Babin BJ, Anderson RE. Multivariate Data Analysis: A global perspective, 7th Ed. New York, NJ: Pearson Global Editions; 2010.

26. Statistical Package for Social Sciences (SPSS) (version 19.0). Armonk, New York. IBM; 2010.

27. Joranson DE, Ryan KM, Gilson AM, Dahl Jl. Trends in medical use and abuse of opioid analgesics. JAMA. 2000;13:1710-1714.

28. Broekmans S, Vanderschueren S, Morlion B, Kumar A, Evers G. Nurses' attitudes toward pain treatment with opioids: a survey in a Belgian University Hospital. Int J Nurs Stud. 2004;41:183-189.

29. McCaffery M, Ferrell BR. Opioids and pain management: what do nurses know? Nursing. 1999;29:48-52.

30. Jonnaert P. Competences and Socio-constructivism: A theoretical framework. Bruxelles, Belgium: De Boeck; 2009.

31. Tardif J. Assessment of Competences: Documentation of the development. Montréal, Canada: Chenelière Éducation; 2006.

32. University of Applied Sciences Western Switzerland (HES-SO). Bachelor of Nursing. Available from: http://www.hes-so.ch/modules/ formation/detail.asp?ID=185. Accessed August 2, 2011.

33. Chang YJ, Yun YH, Park SM, et al. Nurses' willingness to maximize opioids analgesia for severe cancer pain, and its predictor. Support Care Cancer. 2005;13:743-751.

34. Trescot AM, Helm S, Hansen H, Benyamin R, Glaser SE. Opioids in the management of chronic non-cancer pain: An update of American Society of the international Pain Physicians (ASIPP) guidelines. Pain Phys. 2008;11(Opioids Special Issue):11-62.

35. Trescot AM, Glaser SE, Hansen H, Benyamin R. Effectiveness of opioids in the treatment of chronic non-cancer pain. Pain Physic. 2008;11(Opioids Special Issue):181-200.

36. Howell D, Butler L, Vincent L, Watt-Watson J, Stearns N. Influencing nurses' knowledge, attitudes, and practice in cancer pain management. Cancer Nurs. 2000;23(1):55-63.

37. Ballantyne JC, Mao J. Opioid therapy for chronic pain. $N$ Engl Med J. 2003;349:1943-1953.

38. Vallrand A, Nowak LA. Chronic opioid therapy for non-malignant pain: The patients' perspective: Part II Barriers to chronic opioid therapy. Pain Manage Nurs. 2010;11:126-131.

39. Pepin J, Dubois S, Girard F, Tardif J, Ha L. A cognitive learning model of clinical nursing leadership. Nurs Educ Today. 2011;31:268-273.

40. Meyer L. Applying the theory of planned behavior: nursing students' intention to seek clinical experiences using the essential clinical behavior database. J Nurs Educ. 2002;41:107-116.

\section{Dovepress}

resource management, health outcomes, and improving patient safety in all settings. The manuscript management system is completely online and includes a very quick and fair peer-review system. Visit http://www.dovepress.com/testimonials.php to read real quotes from published authors. 